\title{
Aluminium Mediated Isocyanide Insertion and Sequential Ring Opening Cyclization (SROC) Strategy: Synthesis of Azole Fused Benzimidazoquinazoline Skeletons
}

\author{
Anand H. Shinde, Venkata Nagarjuna Babu, Punith S. and Duddu S. Sharada* \\ Department of Chemistry, Indian Institute of Technology Hyderabad, Kandi - 502 284, Sangareddy, Telangana, INDIA \\ Phone: (040) 2301 6257; Fax: (040) 2301 6032, E-mail: sharada@chy.iith.ac.in
}

Supporting Information Placeholder

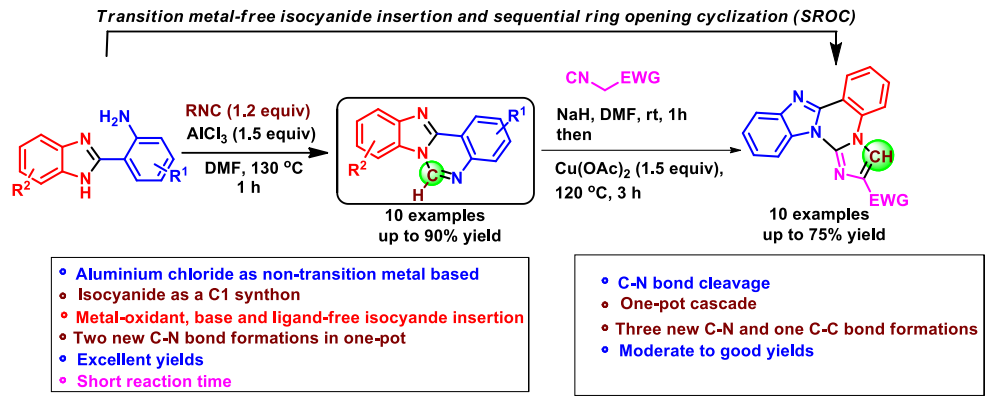

ABSTRACT: A first report on transition-metal-free aluminium chloride mediated isocyanide insertion between two amine nucleophiles have been presented. Also, an unusual C-N bond cleavage allow for the further development of copper mediated ring opening cyclization (SROC) strategy for the synthesis of azole fused benzimidazoquinazoline scaffolds. The key features of this protocol are aluminium chloride as non-transition-metal based mediator, oxidant/base/ligand free isocyanide insertion, three new $\mathrm{C}$-N and one $\mathrm{C}-\mathrm{C}$ bond formations and simultaneous construction of multiprivileged azole fused benzimidazoquinazoline in good yields.

The $\mathrm{C} 1$ insertions leading to $\mathrm{C}-\mathrm{C} / \mathrm{C}-\mathrm{X}$ for the synthesis of annulated heterocycles have been explored via transition metal catalysis by using various reagents such as $\mathrm{DMF},{ }^{1 \mathrm{a}} \mathrm{MeOH},{ }^{1 \mathrm{~b}}$ DMSO, ${ }^{\text {la }}$ NMP, ${ }^{\text {la }}$ TMEDA, ${ }^{\text {la }} \mathrm{CO}^{1 \mathrm{c}}$ and isocyanides. ${ }^{2}$ Among which isocyanide due to its peculiar intrinsic ambiphilic property and its affinity towards metal has been widely explored as $\mathrm{C} 1$ synthon in the synthesis of nitrogen heterocycles. The ambiphilic nature of isocyanide have been widely used for the synthesis of medicinally and biologically important diverse heterocycles. ${ }^{2}$ Further, isocyanides have been successfully employed as C1 synthon in cycloaddition reactions ${ }^{3}$ (Scheme $1 \mathrm{a}$ and Ref. 2). Moreover, recently Chatani et al. ${ }^{4}$ have explored ambiphilic nature of isocyanide by $\mathrm{AlCl}_{3}$ mediated insertion between aromatic $\mathrm{CH}$-bond of comparatively weak nucleophilic indole (Scheme 1b). On the other hand, the unique affinity of isocyanide towards metals has been explored with transition metals such as palladium, cobalt and nickel catalyzed insertions between various bisnucleophiles in recent times. ${ }^{5}$ However, non-transition metal based/transition metal-free isocyanide insertion between two nucleophiles is unprecedented till date. Moreover, recently we reported the nickel catalyzed a base/oxidant free isocyanide insertion in 2aminobenzimidazole $^{6}$ (Scheme 1c) which intrigued us to develop a transition metal free isocyanide insertion. However, while working on the idea we observed the formation of benzimidazoquinazoline $(\mathrm{BzQ})$ via deaminated isocyanide insertion between two amine nucleophiles by using aluminium
Scheme 1 Strategies using isocyanide as $\mathrm{C1}$ source

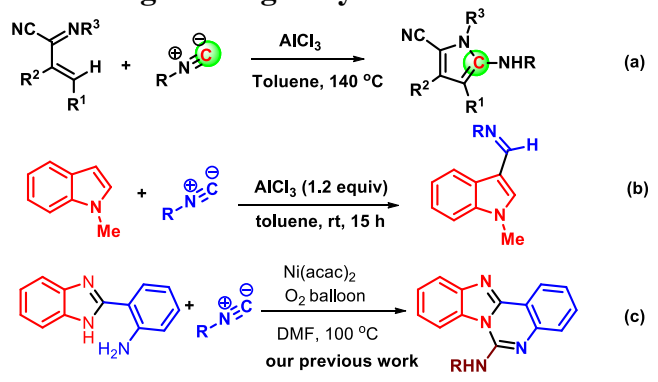

chloride as mediator. The BzQ framework is common among the privileged heterocycles possessing good spectrum of activities such as antimalarial, ${ }^{7 \mathrm{a}}$ anti-inflammatory, ${ }^{7 \mathrm{~b}}$ anticonvulsant, ${ }^{7 \mathrm{c}}$ antidiabetic, ${ }^{7 \mathrm{~d}}$ and antitumor ${ }^{7 \mathrm{e}}$ activities. Among them benzimidazo[1,2-c]quinazolines such as Erlotinib alkaloid (Figure 1, I) and its analogues (Figure 1, II) showed a good anticancer activity. ${ }^{8}$ Similarly, imidazole based skeletons are highly privileged in nature which show several bioactivities which includes drug molecule Omeprazole (Figure 1, III) (a good proton pump inhibitor) and Ondansetron (Figure 1, IV) (used to suppress the nausea caused by cancer chemotherapy). Owing to the importance of BzQs, several methodologies were reported for its synthesis. ${ }^{9} \mathrm{We}$ envisioned to use this interesting amidine containing BzQ product in Van-Leusen reaction for the synthesis of azole fused BzQ. However, we observed 


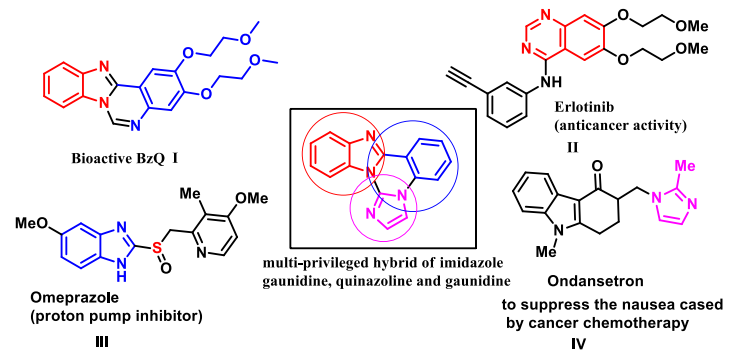

Figure 1 Representative privileged bioactive molecules

an interesting and unusual ring opened Van-Leusen type product. We hypothesized to use this ring opened product for the synthesis of regiodivergent azole fused BzQ through an overall ring-opening cyclization sequence from BzQ. Recently, ring opening cyclization reactions ${ }^{10}$ for the synthesis of various heterocycles have gained importance due to its domino and sustainable nature to transform one heterocycle into other privileged heterocycle (Scheme $2 \mathrm{a}$ ). There are only couple of reports for the synthesis of azole fused BzQ viz. coppercatalyzed cascade of diimide ${ }^{11 a}$ and palladium catalyzed Ullmann-CDC sequence ${ }^{1 \mathrm{~b}}$ (Scheme 2b). In continuation of our research interests in isocyanide insertions ${ }^{12 a, 6}$ and annulation strategies, ${ }^{12 b, 12 \mathrm{c}}$ herein, we have demonstrated for the first time a non-transition metal mediated isocyanide insertion followed by ROC sequence for the synthesis of privileged azole fused BzQs as shown in Scheme 2c.

Scheme 2 Previously reported ROC strategy and synthesis of azole fused $\mathrm{BzQs}$

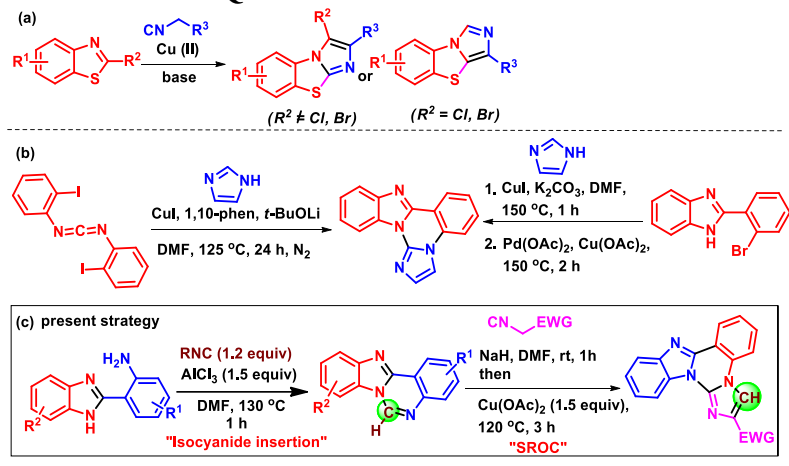

Our initial attempts were directed towards the optimization of isocyanide insertion strategy (Table 1). It is to be noted that there were only traces of product in absence of mediator (Entry 1). When we performed the reaction of amine 3a with cyclohexylisocyanide $\mathbf{4 a}$ in toluene solvent using $\mathrm{AlCl}_{3}$ as promoter at $110^{\circ} \mathrm{C}$, pleasingly afforded the deaminative product BzQ 5aa compound in $62 \%$ yield (Entry 2). Later we have screened various solvents such as chlorobenzene, $p$-xylene, DMSO, DCE and DMF (Entries 3-8) which gave up to $90 \%$ of yield in DMF as solvent with increased equivalents of $\mathrm{AlCl}_{3}$ and isocyanide (Entry 8). There was no further increment in the yield by increasing equivalents of either $\mathrm{AlCl}_{3}$ or isocyanide (Entries 9 and 10). The reaction with other isocyanides was unsatisfactory (see SI for isocyanide screening and detailed optimization). So, finally we chose 1.5 equivalents of aluminium chloride, 1.2 equivalents of isocyanide and DMF as solvent at $130{ }^{\circ} \mathrm{C}$ as satisfactory optimized condition (Entry 8).
Table 1. Optimization for deaminative isocyanide insertion strategy $^{a, b}$

\begin{tabular}{|c|c|c|c|c|}
\hline Entry & Reagent/CyNC (equiv) & Solvent & Temp & Yield \\
\hline 1 & - & Toluene & 110 & trace \\
\hline 2 & $\mathrm{AlCl}_{3}(1.2) / \mathrm{CyNC}(1)$ & Toluene & 110 & 62 \\
\hline 3 & $\mathrm{AlCl}_{3}(1.5) / \mathrm{CyNC}(1)$ & Chlorobenzene & 130 & 80 \\
\hline 4 & $\mathrm{AlCl}_{3}(1.5) / \mathrm{CyNC}(1.2)$ & $P$-Xylene & 130 & 70 \\
\hline 5 & $\mathrm{AlCl}_{3}(1.5) / \mathrm{CyNC}(1.2)$ & Chlorobenzene & 130 & 88 \\
\hline 6 & $\mathrm{AlCl}_{3}(1.5) / \mathrm{CyNC}(1.2)$ & DMSO & 130 & 40 \\
\hline 7 & $\mathrm{AlCl} 3$ (1.5)/CyNC (1.2) & DCE & 100 & 82 \\
\hline 8 & $\mathrm{AlCl}_{3}(1.5) / \mathrm{CyNC}(1.2)$ & DMF & 130 & 90 \\
\hline 9 & $\mathrm{AlCl}_{3}(2) / \mathrm{CyNC}(1.2)$ & DMF & 130 & 88 \\
\hline 10 & $\mathrm{AlCl}_{3}(1.5) / \mathrm{CyNC}(2)$ & DMF & 130 & 89 \\
\hline
\end{tabular}

${ }^{a}$ Reaction conditions: Amine 3a $(0.5 \mathrm{mmol}), \mathrm{CyNC} 4 \mathbf{4 a}(0.5 \mathrm{mmol})$ and solvent $2 \mathrm{~mL} .{ }^{b}$ Yield of isolated product after column chromatography.

With this optimized conditions, we have checked the scope of various 2-aminophenylbenzimidazoles, which provided the products in high to excellent yields (5aa-5af, Scheme 3). We have also checked the feasibility of one-pot synthesis of $\mathbf{5}$ directly from isatoic anhydride $\mathbf{1}$ in sequential manner which also provided the products however with comparatively less yields (5aa, 5cb-5ae, 5ag, Scheme 3).

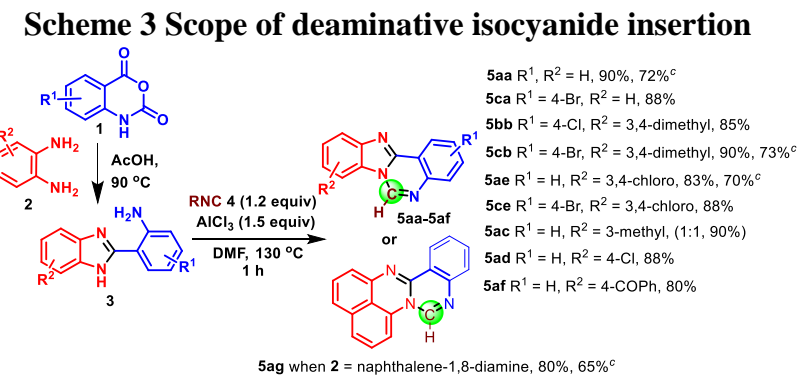

\footnotetext{
${ }^{a}$ General conditions: Amine 3aa $(0.5 \mathrm{mmol})$, cyclohexyl isocyanide 4a $(0.6 \mathrm{mmol})$, aluminium chloride $(0.75 \mathrm{mmol})$ and DMF $(2 \mathrm{~mL}) ;{ }^{b}$ Isolated yields after column chromatography. ${ }^{c}$ One-pot yield from $1 \mathbf{a}$
}

After having developed the isocyanide insertion strategy we started to optimize the SROC strategy (Table 2). We found the $\mathrm{NaH}$ as the best base for ring opening (see SI for screening of base and detailed optimization). By keeping these ring opening conditions constant, we screened various conditions for further cyclization and it is to be noted that the reaction in absence of any copper source did not provided even traces of the cyclized product (Entry 1). Later, we screened various copper sources such as $\mathrm{CuCl}_{2}, \mathrm{CuI}, \mathrm{CuBr}, \mathrm{CuBr}_{2}$ and $\mathrm{Cu}(\mathrm{OAc})_{2} \cdot \mathrm{H}_{2} \mathrm{O}$ in DMF under reflux conditions (Entries 2-6) which pleasingly provided the product 7aac albeit in $50 \%$ yield in case of $\mathrm{Cu}(\mathrm{OAc})_{2} \cdot \mathrm{H}_{2} \mathrm{O}$ as copper source (Entry 6). When we used anhydrous copper acetate at various temperatures (Entries 7-8) it resulted in the product up to $69 \%$ yield at $120{ }^{\circ} \mathrm{C}$ (Entry 8). Significantly, the increase in amount of copper source up to 1.5 equiv could able to improve the yield up to $75 \%$ yield (Entry 9), however our attempts of further increase or decrease in the amount of copper source were not fruitful (Entries 10 and 11). Our attempts to check the progress 
of reaction under catalytic version led to trace amount of the product (Entry 12). Hence, we chose the reaction with 1.5 equiv of copper acetate at $120^{\circ} \mathrm{C}$ under DMF solvent as the optimized reaction condition (Entry 9) for checking scope of the SROC strategy.

Table 2 Optimization for ring opening cyclization (ROC) strategy ${ }^{a, b}$

\begin{tabular}{|c|c|c|c|c|}
\hline Entry & Copper source/Ligand & Solvent & Temp & Yield $(\%)$ \\
\hline 1 & - & DMF & reflux & 0 \\
\hline 2 & $\mathrm{CuCl}_{2}(1)$ & DMF & reflux & 20 \\
\hline 3 & $\mathrm{CuI}(1)$ & DMF & reflux & 10 \\
\hline 4 & $\mathrm{CuBr}(1)$ & DMF & reflux & 15 \\
\hline 5 & $\mathrm{CuBr}_{2}(1)$ & DMF & reflux & 30 \\
\hline 6 & $\mathrm{Cu}(\mathrm{OAc})_{2} \cdot \mathrm{H}_{2} \mathrm{O}(1)$ & DMF & reflux & 50 \\
\hline 7 & $\mathrm{Cu}(\mathrm{OAc})_{2}(1)$ & DMF & reflux & 55 \\
\hline 8 & $\mathrm{Cu}(\mathrm{OAc})_{2}(1)$ & DMF & 140 & $60,69,{ }^{c} 20^{d}$ \\
\hline 9 & $\mathrm{Cu}(\mathrm{OAc})_{2}(1.5)$ & DMF & 120 & 75 \\
\hline 10 & $\mathrm{Cu}(\mathrm{OAc})_{2}(2)$ & DMF & 120 & 76 \\
\hline 11 & $\mathrm{Cu}(\mathrm{OAc})_{2}(0.5)$ & DMF & 120 & 30 \\
\hline 12 & $\mathrm{Cu}(\mathrm{OAc})_{2}(0.2) / \mathrm{PPh}_{3}(0.4$ & DMF & 120 & trace \\
\hline
\end{tabular}

${ }^{a}$ Reaction conditions: 5aa $(0.5 \mathrm{mmol})$, ethylisocyanoacetate $4 \mathbf{b}(0.6$ $\mathrm{mmol}), \mathrm{NaH}(0.6 \mathrm{mmol})$, copper source and DMF $2 \mathrm{~mL} .{ }^{b}$ Yield of isolated product after column chromatography. ${ }^{b}$ Reaction temp $120{ }^{\circ} \mathrm{C} .{ }^{c}$ Reaction temp $100^{\circ} \mathrm{C}$.

With this optimized condition in hand, further we envisaged to examine the scope of the reaction with respect to various 2-aminophenylbenzimidazole $\mathbf{3}$ by following two step sustainable approach viz. aluminium chloride mediated deaminative isocyanide insertion and SROC strategy involving a simple work-up and avoiding column chromatography of intermediate $\mathbf{5}$. When we used various electron donating as well as electron-withdrawing 2-aminophenylbenzimizole $\mathbf{3}$ and isocyanides $\mathbf{4}$ such as ethylisocyanoacetate $\mathbf{4 b}$ and TOSMIC $\mathbf{4 c}$ it afforded the desired products $7 \mathbf{a a b}-7 \mathbf{a c b}$ in moderate to good yields $(65-75 \%$, Table 3$)$.

Initially when we used unsubstituted 2-aminophenylbenzimidazole 3aa it gave the desired product in $75 \%$ yield (7aab). Also, the electron donating dimethyl substitution over benzimidazole such as 3ab gave the product $\mathbf{7 a b b}$ in $75 \%$ yield. When we used the electron withdrawing benzimidazoles such as 3ba and 3ca also worked well in the reaction which gave the desired product in $70 \%$ yields (7bab and $7 \mathbf{c a b}$ ). Later we tested the benzimidazoquinazoline with electron donating methyl substitution over benzimidazole part and electron withdrawing bromo substitution over quinazoline part such as $\mathbf{5} \mathbf{c b}$ which is tolerated well in the reaction giving the product 7cbb in $72 \%$ yield. Delightfully employing TOSMIC $\mathbf{4 c}$ in the reaction worked smoothly to give the products in 7aac and 7 cac in $72 \%$ and $66 \%$ yields respectively. The unsymmetrical benzimidazole such as 3ac gave the products in good to moderate yields $(73-65 \%)$ however, with 1:1 mixture of regioisomers (7acb and 7acc). However, the unsymmetrical benzimidazole such as 3ad with chloro substitution led to the single regioisomer in 66\% yield (7adb). Further the substrates with napthyl substitution and strong electron withdrawing nitro substituted compounds failed to give the expected products (7aeb and 7ahb).

Table 3 Scope of the reaction ${ }^{a, b}$
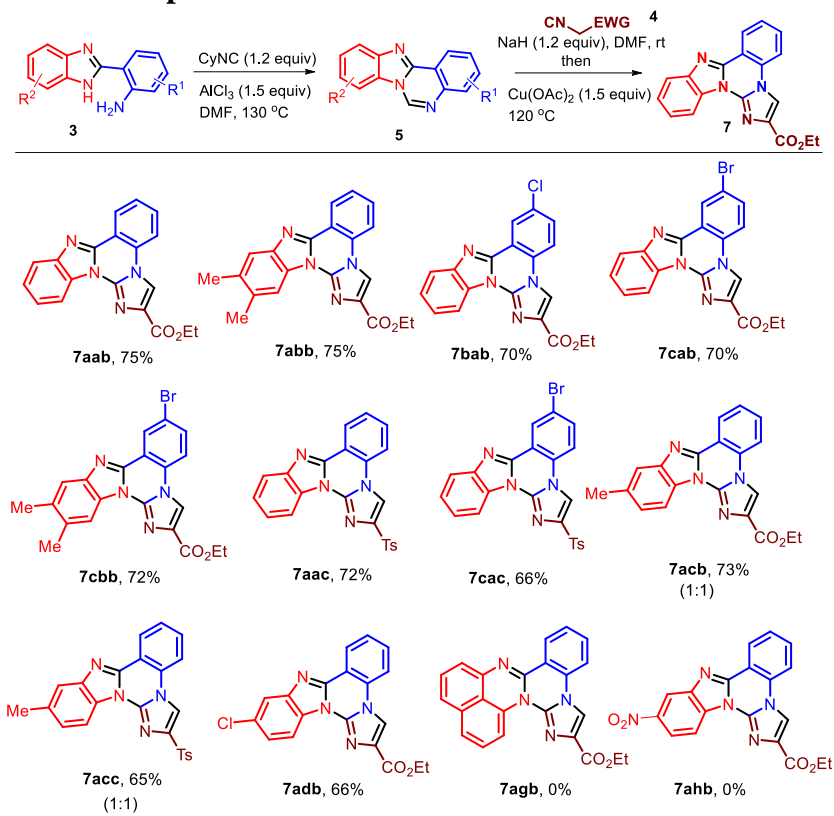

${ }^{a}$ Reaction conditions: $3(0.2 \mathrm{mmol})$, CyNC 4a $(0.24 \mathrm{mmol}), \mathrm{AlCl}_{3}(0.3$ $\mathrm{mmol})$ and DMF $(1.5 \mathrm{~mL})$; isocyanide $4(0.24 \mathrm{mmol}), \mathrm{NaH}(0.24 \mathrm{mmol})$, DMF $(1.5 \mathrm{~mL})$ and $\mathrm{Cu}(\mathrm{OAc}) 2(0.3 \mathrm{mmol}) ;{ }^{b}$ Isolated yields after column chromatography.

Based on the literature study, ${ }^{4,10 a}$ and the isolated intermediate acyclic imidazole product 6aac (CCDC-1532830, see SI for X-ray data of intermediate 6aac), we proposed a plausible mechanism as depicted in Figure 2. Initially, there is formation of isocyanide-aluminium chloride complex $\mathbf{A}$ which on further attack of 3aa results in intermediate $\mathbf{B}$. The intermediate $\mathbf{B}$ rearranges via proton shift to afford intermediate $\mathbf{C}$ which on intramolecular nucleophilic attack of imidazolium nitrogen gives the intermediate D. Further, demetallation followed by deamination affords the compound 5aa. The attack of anion $\mathbf{F}$ on the imine 5aa generates intermediate $\mathbf{G}$ which on annulation and $\mathrm{C}-\mathrm{N}$ bond cleavage gives ring opened product 6. The compound 6, forms the copper (II) complex I which cyclizes to copper (II) complex $\mathbf{J}$ followed by subsequent reductive elimination affords the desired product 7 .

In conclusion, we have developed a distinct two-step strategy involving a novel aluminium chloride mediated nontransition metal based isocyanide insertion and SROC strategy involving copper mediated regio divergent synthesis of azole fused BzQs. An interesting ROC sequence on cyclic amidines via unusual Van-Leusen reaction leading to regiodivergent azole-fused BzQs is noteworthy. The present unprecedented metal-oxidant, ligand and base free deaminative isocyanide insertion make the strategy unique. The salient features of this method are formation of three new $\mathrm{C}-\mathrm{N}$ bonds, rapid access to biologically relevant heterocyclic scaffolds, short reaction time, high bond forming index (BFI), and the use of inexpensive, readily available starting materials. The diverse potential of the present SROC strategy has been demonstrated by synthesizing naphthalene fused quinazoline compounds. Further 
studies on aluminium mediated isocyanide insertions and exploration of ROC strategy are currently underway.

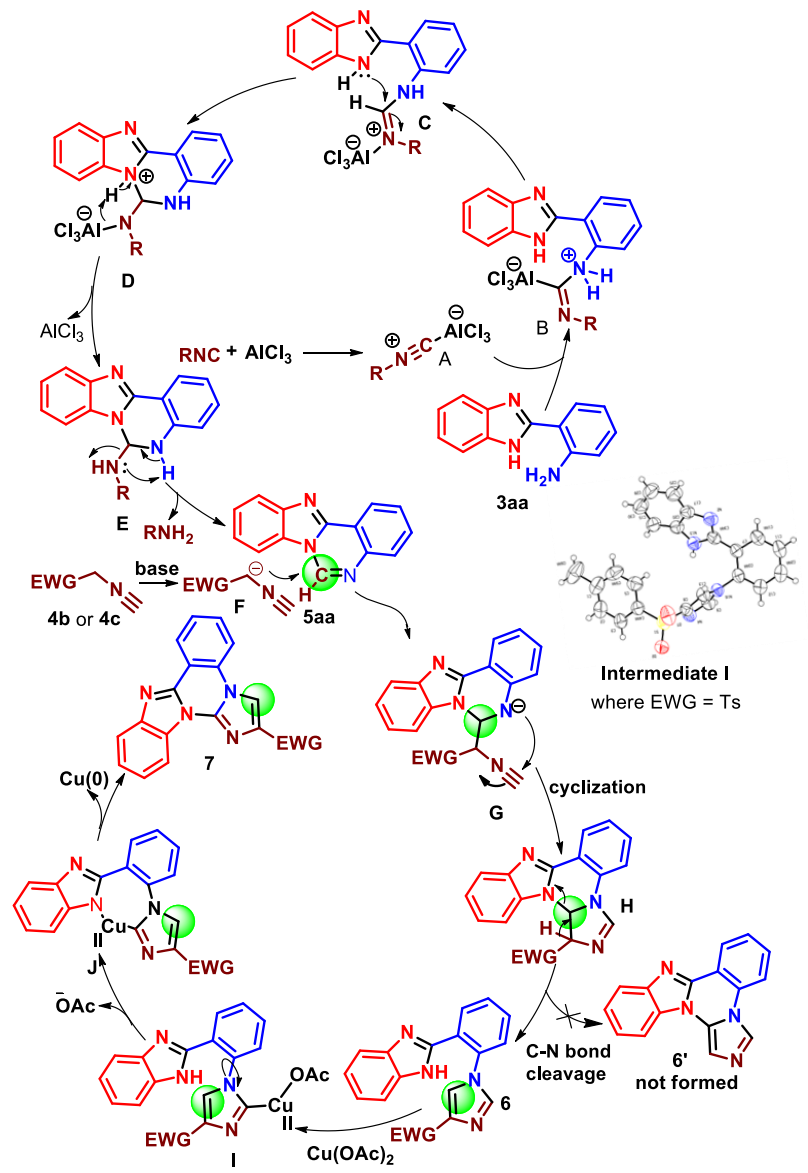

Figure 2 Plausible reaction mechanism for deaminative isocyanide insertion and SROC strategy for the synthesis of $\mathbf{7 .}$

\section{ASSOCIATED CONTENT}

\section{Supporting Information}

The Supporting Information is available free of charge on the ACS Publications website.

Experimental procedures, characterization data, and copies of NMR (PDF).

Crystallographic data for compound $\mathbf{6 a a c}(\mathrm{CIF})$.

\section{AUTHOR INFORMATION}

\section{Corresponding Author}

*E-mail: sharada@iith.ac.in

\section{ACKNOWLEDGMENT}

We gratefully acknowledge the Council of Scientific and Industrial Research (CSIR 02(0297)/17/EMR-II), New Delhi, IIT Hyderabad for financial support. AHS and VNB thank UGC, PS thank CSIR, New Delhi, India for the award of research fellowship.

\section{ORCID}

Duddu S. Sharada: 0000-0001-5861-4126

Anand H. Shinde: 0000-0003-1966-8505
Punith S.: 0000-0003-3649-0630

\section{REFERENCES}

(1) (a) Lv, Y.; Li, Y.; Xiong, T.; Pu, W.; Zhang, H.; Sun, K.; Liu, Q.; Zhang, Q. Chem. Commun. 2013, 49, 6439. (b) Natte, K.; Neumann, H,; Beller, M.; Jagadeesh, R. V. Angew. Chem. Int. Ed. 2017, 56, 6384. (c) Brennführer, A.; Neumann, H.; Beller, M. ChemCatChem 2009, 1, 28.

(2) (a) Gulevich,A. V.; Zhdanko, A. G.; Orru, R. V. A.; Nenajdenko, V. G. Chem. Rev. 2010, 110, 5235. (b) Vlaar, T.; Ruijter, E.; Maes, B. U. W.; Orru, R. V. A. Angew. Chem. Int. Ed. 2013, 52, 7084. (c) Lang, S. Chem. Soc. Rev. 2013, 42, 4867.

(3) (a) Chatani, N.; Oshita, M.; Tobisu, M.; Ishii, Y.; Murai, S. J. Am. Chem. Soc. 2003, 125, 7812. (b) Fontaine, P.; Masson, G.; Zhu, J. Org. Lett. 2009,11, 1555. (c) Ito, Y.; Kato, H.; Saegusa, T. J. Org. Chem. 1982, 47, 743.

(4) Tobisu, M.; Yamaguchi, S.; Chatani, N. Org. Lett. 2007, 9, 3351.

(5) (a) Qiu, G.; Ding, Q.; Wu, J. Chem. Soc. Rev. 2013, 42, 5257. (b) Vlaar, T.; Mampuys, P.; Helliwell, M.; Maes, B. U. W.; Orru, R. V. A.; Ruijter, E. J. Org. Chem. 2013, 78, 6735. (c) Estévez, V.; Van Baelen, G.; Lentferink, B. H.; Vlaar, T.; Janssen, E.; Maes, B. U. W.; Orru, R. V. A.; Ruijter, E. ACS Catal. 2014, 4, 40-43. (d) Vlaar, T.; Cioc, R. C.; Mampuys, P.; Maes, B. U. W.; Orru, R.V. A.; Ruijter, E. Angew. Chem. 2012, 124, 13235. (e) Zhu, T. -H.; Wang, S. -Y.; Wang, G. -N.; Ji, S. J. Chem. Eur. J. 2013, 19, 5850. (e) Rajesh, M.; Thirupati, N.; Reddy, T. J.; Kanojiya, S.; Reddy, M. S. J. Org. Chem. 2015, 80, 12311.

(6) Shinde, A. H.; Arepally, S.; Baravkar M. D.; Sharada, D. S.; J. Org. Chem. 2017, 82, 331 .

(7) (a) Verhaeghe, P.; Azas, N.; Gasquet, M.; Hutter, S.; Ducros, C.; Laget, M.; Rault, S.; Rathelot, P.; Vanelle, P. Bioorg. Med. Chem. Lett. 2008, 18, 396; (b) Smits, R. A.; Adami, M.; Istyastono, E. P.; Zuiderveld, O. P.; van Dam, C. M. E.; de Kanter, F. J. J.; Jongejan, A.; Coruzzi, G.; Leurs, R.; de Esch, I. J. P. J. Med. Chem. 2010, 53, 2390. (c) Kashaw, S. K.; Kashaw, V.; Mishra, P.; Jain, N. K.; Stables, J. P. Eur. J. Med. Chem. 2009, 44, 4335. (d) Malamas, M. S.; Millen, J. J. Med. Chem. 1991, 34, 1492. (e) Chilin, A.; Conconi, M. T.; Marzaro, G.; Guiotto, A.; Urbani, L.; Tonus, F.; Parnigotto, P. J. Med. Chem. 2010, 53, 1862.

(8) Shen, C.; Wang, L.; Wen, M.; Shen, H.; Jin, J.; Zhang, P. Ind. Eng. Chem. Res. 2016, 55, 3177.

(9) (a) Khajavi, M. S.; Rad-moghadam, K.; Hazarkhani, H. Synth. Commun. 1999, 29, 2617. (b) Liu, Q.; Yang, H.; Jiang, Y.; Zhao, Y.; Fu, H. RSC $A d v$. 2013, 3, 15636. (c) Mirallai, S. I.; Koutentis, P. A. J. Org. Chem. 2015, 80, 8329.

(10) (a) Wang, J.; Li, J.; Zhu, Q. Org. Lett. 2015, 17, 5336. (b) Liu, Y.; Jin, S.; Huang, L.; Hu, Y. Org. Lett. 2015, 17, 2134. (c) Qi, X.; Xiang, H.; Yang, C. Org. Lett. 2015, 17, 5590. (d) Zhang, L.; Zhang, X.; Lu, Z.; Zhang, D.; Xu, X. Tetrahedron 2016 ,72, 7926.

(11) (a) Yuan, G.; Liu, H.; Gao, J.; Yang, K.; Niu, Q.; Mao, H.; Wang, X.; Lv, X. J. Org. Chem. 2014, 79, 1749. (b) Nandwana, N. K.; Pericherla, K.; Kaswan, P.; Kumar, A. Org. Biomol. Chem. 2015, 13, 2947.

(12) (a) Vidyacharan, S.; Murugan, A.; Sharada, D. S. J. Org. Chem. 2016, 81, 2837. (b) Sharada, D. S.; Shinde, A. H.; Patel, S. M.; Vidyacharan, S. J. Org. Chem. 2016, 81, 6463. (c) Arepally, S.; Babu, V. N.; Bakthadoss, M.; Sharada, D. S. Org. Lett. 2017, 19, 5014. 